\title{
Mechanical characterization and reinforcement of the adobe material of the Chellah archaeological site
}

\author{
Sana SIMOU $^{1 *}$, Khadija BABA ${ }^{1}$, Nacer AKKOURI ${ }^{1}$, Mohammed LAMRANI ${ }^{1}$, Mohammed TAJAYOUT ${ }^{1}$, \\ and Abderrahmane NOUNAH ${ }^{1}$ \\ ${ }^{1}$ Civil Engineering and Environment Laboratory - High School of Technology, Sale, Civil Engineering, Water, \\ Environment and Geosciences Centre (CICEEG), Mohammadia School of Engineering, Mohammed V University Rabat, \\ Morocco
}

\begin{abstract}
The evaluation of historical buildings has always posed significant challenges due to the difficulties associated with the characterization of complex geometries, the variability of the properties of building materials and the actual state of damage to these structures. This challenge is even more complex when it concerns historical adobe masonry buildings, because earthen masonry has a high variability and rapid deterioration over time if it is not properly maintained. In the context of the previous, it was important to provide information to support intervention projects in historic centres. This research involves the experimental analysis of the adobe material collected from the Chellah archaeological site (Rabat-Morocco), in order to study the mechanical behaviour of this material as well as that reinforced by wood shaving. A series of mechanical tests carried out, which include compressive and tensile strength on the adobe material and the mixture adobe/wood fibre in different proportions. The improvement of the mechanical properties of the reinforced adobe, led us to a SEM study, which was carried out on the surface of the test specimens to examine the morphology and observe the interfaces of the adobe/wood mixture, as well as the state of dispersion of the fibres in the adobe mixture.
\end{abstract}

\section{Introduction}

Monuments and historical remains built of adobe material show that this material can persist for centuries[1]. As with the cultural and historical heritage of the city of Rabat (Morocco), Chellah is one of the most historically significant monuments, this site being the melting pot of several civilizations that have played a major role (7th-6th century $\mathrm{BC}$ )[2], including the Marinid who left traces of Islamic architecture through the Medersa site built by the adobe construction technique [3]. The adobe material is composed of adequate proportions of gravel, sand, silt, clay, and water, and it is produced by beating and compacting soil in a formwork[4]. In recent years, there has been occasional recourse to the rehabilitation and reinforcement of adobe buildings by some owners who are aware of its preservation and protection[5]. The rehabilitation option presents difficulties related to the lack of information on the properties and characteristics of the mechanical behaviour of adobe, indeed technical studies are needed to determine properties such as: modulus of elasticity, compressive, tensile and shear strength, and its composition [6]. The improvement of the soil using a stabilizer and an appropriate reinforcement material, natural or artificial, improves not only its durability but also its compressive strength, the latter increases considerably by adding fibres[7]. Different stabilizers produce different impacts on the soil's durability. The most commonly used natural stabilizers are jute, sisal, straw, rice husk, sugar cane bagasse[8], and soluble silanes or siloxanes, isocyanates, lime, cement, plaster, basalt pumice [9] are among the most frequently used synthetic stabilizers. In this context, samples of adobe taken from the Chellah site were mixed with different wood shaving contents. In the case, wood fibre materials have a thermal conductivity close to that of expanded polystyrene and glass wool [10]. In addition, they are easy to use for both new construction and renovations. They also have other advantages such as excellent sound isolation due to their ability to absorb sound waves[11]. Another major advantage of adding wood shaving to building materials is that they are inexpensive, available in large quantities, environmentally friendly and easy to process [12-14].

The experimental program consisted in a first step of physical characterization including an analysis of the granulometric distribution of the material and a statistical analysis of the content of the wood fibres added to the mix of the adobe by volume, in the second step a study of uniaxial compression tests on cylindrical samples, and bending tensile tests on prismatic samples according to the three-point loading schema. These tests make it possible to evaluate the strength capacity of the specimen, and the evolution of rigidity and deformation with the increase in the content of wood shaving. In addition, a complementary study by scanning electron microscope was carried out on samples on the surface of the test specimens to examine the morphology and to observe the interfaces of the wood fibres and the adobe matrix. The methodology applied in this study provides promising results to better predict for the mechanical properties used in construction and to further reduce costly experimental work.

Corresponding author: sanae.simou@gmail.com 


\section{Materials and methods}

\subsection{Materials and proportions of the mixture}

The adobe material used in this study comes from the Chellah archaeological site (latitude: 34.006686, longitude: -6.820532), it is a mixture of gravel and sand, clay and silt. Wood shaving are made of Scotch pine tree waste produced from woodworking activities Fig.1 and have an irregular shape, with a particle size distribution between $2 \mathrm{~mm}$ and $30 \mathrm{~mm}$. The apparent density of the shaving is about $46.8 \mathrm{~kg} / \mathrm{m} 3$.
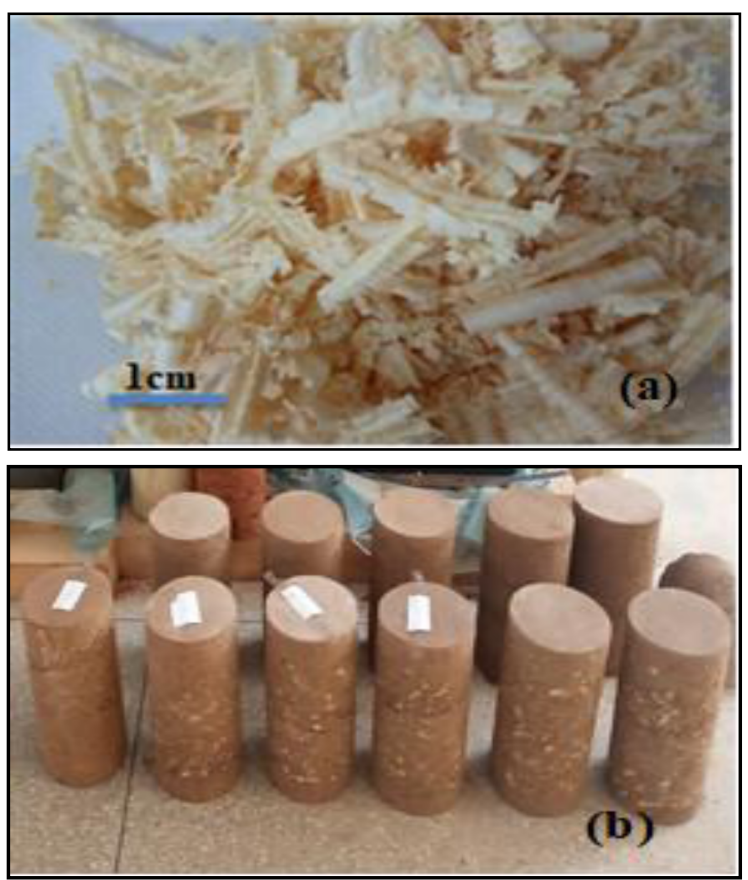

Fig.1. (a) Wood shaving (b) cylindric specimens with wood shaving.

Two different mixtures were prepared: a reference mixture composed only of adobe soil and a mixture with wood shaving in different proportions: $10 \%, 20 \%, 30 \%$, $40 \%, 50 \%, 60 \%$, and $70 \%$ by volume of wood shaving. The water content on the mixtures was determined by the Proctor test. Table 1 summarizes the different mixing ratios and dry densities of samples with wood shaving. Two types of specimens were manufactured for this study Fig.2

Table 1. Proportion of the mixture and dry density of the samples.

\begin{tabular}{|c|c|c|}
\hline $\begin{array}{c}\text { Proportio } \\
\text { ns of wood } \\
\text { shaving } \\
(\%)\end{array}$ & $\begin{array}{c}\text { Water } \\
\text { content (\%) }\end{array}$ & $\begin{array}{c}\text { Dry density } \\
\left.\text { (kg.m }^{-3}\right)\end{array}$ \\
\hline 0 & 13.3 & 1883,0 \\
\hline 10 & 15.38 & 1699,7 \\
\hline 20 & 17 & 1589,2 \\
\hline
\end{tabular}

\begin{tabular}{|c|c|c|}
\hline 30 & 19 & 1720,9 \\
\hline 40 & 19.25 & 1679,5 \\
\hline 50 & 20.51 & 1761,2 \\
\hline 60 & 21.98 & 1659,9 \\
\hline 70 & 21.9 & 1559 \\
\hline
\end{tabular}

Cylindrical specimens $160 \mathrm{~mm}$ in diameter and $320 \mathrm{~mm}$ high intended for compressive strength testing. To perform the bending tensile tests, rectangular prismatic specimens $(40 \times 40 \times 160) \mathrm{mm}$ were manufactured.

All samples were left in the open air for four weeks, and then put in an oven to be dried at $60^{\circ} \mathrm{C}$ for 24 hours, and then the temperature was raised to $100^{\circ} \mathrm{C}$. The specimens were then stored in a controlled room at $20^{\circ} \mathrm{C}$ and $50 \%$ relative humidity $(\mathrm{RH})$ and were tested when they were in equilibrium with the environment about two weeks later.
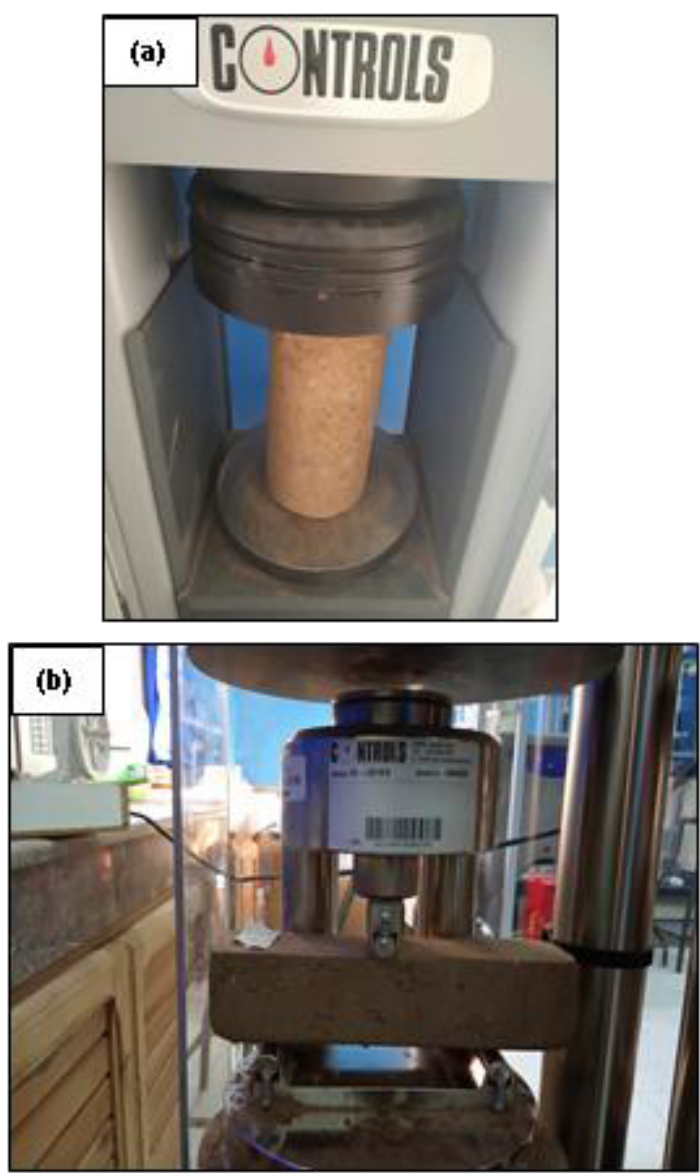

Fig.2. (a) Compressive test (b) Three-point bending test 


\subsection{Geotechnical identification}

Several laboratory tests are carried out, with reference to French standards. The determination of the granulometric distribution indicates that the formulation of the adobe soil corresponds to a mixture of $9 \%$ gravel, $52.5 \%$ sand, $22.5 \%$ clay, with a significant fraction of silt about $16 \%$.

The consistency study was conducted on the basis of the Atterberg limits, which are respectively: plastic limit $\mathrm{W}_{\mathrm{p}}=25.90 \%$ and liquid limit $\mathrm{WL}=33.37 \%$, and the plasticity index was calculated as the difference between the liquidity limit and the plasticity limit $\mathrm{I}_{\mathrm{p}}=7.47 \%$. For the normal Proctor optimum, the water content $\left(\mathrm{W}_{\mathrm{opt}}\right)$ and the maximum dry density $\gamma_{\mathrm{d} \text { max }}$, are respectively $13.3 \%$, and $1.87 \mathrm{~g} / \mathrm{cm}^{3}$. The VBS value is 1.33 . The characteristics of the grain, as well as data from the documentation of the seismic regulations earth structures [15] indicate that this material is appropriate for the chosen purpose.

\subsection{Microscopic observations}

Observations were made on a cross-section of the fracture surface after the tensile test. The scanning electron microscope used is mini Scanning Electron Microscope (mini SEM) HIROX SH 4000M Fig.3. equipped with SE (Secondary Electron) and BSE (BackScattered Electron) detectors. It can provide Image Observation Ready within 2 min.

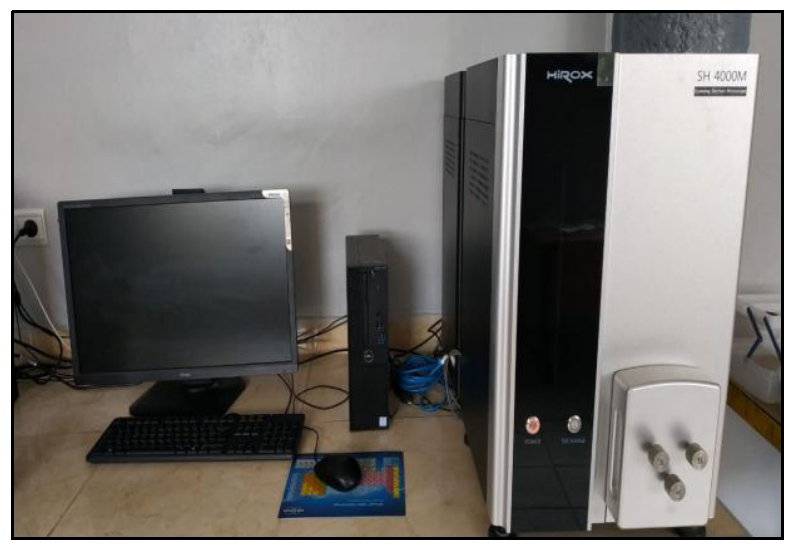

Fig.3. Scanning Electron Microscope (SEM)

\section{Results and discussion}

\subsection{Compressive test}

Bui Quoc-Bao and his collaborators studied the compressive strength of the adobe in the perpendicular and parallel directions to the beds on prismatic samples, which gave results that are not very different [16] to the other results of the simple compression of the other studies[17]. The compressive strength of unstabilized soil increases from a few tenths of MPa for air-dried soil ( 0.5 to $1.5 \mathrm{MPa}$ for cob; 1.0 to $2.5 \mathrm{MPa}$ for adobe) to a few $\mathrm{MPa}$ for compacted soil (1 to $4 \mathrm{MPa}$ ) and compressed blocks (1 to $7 \mathrm{MPa}$ ) [18]. Several studies have concluded that there has been a significant improvement in compressive strength through the addition of stabilizing additives $[16,19,20]$.

Samples were prepared to investigate the compressive strength and important characteristics of the adobe material (six samples) and the adobe material containing wood shaving as an additive. Thirteen cylindrical (160x320) mm samples were subjected to compression tests Fig.2. The tests were carried out according to EN 196-1[21].

The compressive strength results of the adobe material are presented in Table 2 the average compressive strength value is approximately $0,54 \mathrm{MPa}$.

Table 2. Compressive strength obtained from the tests on cylindric samples of adobe material

\begin{tabular}{|c|c|}
\hline Specimens & Stress (MPa) \\
\hline S1 & 0,48 \\
\hline S2 & 0,50 \\
\hline S3 & 0,53 \\
\hline S4 & 0,50 \\
\hline S5 & 0,58 \\
\hline S6 & 0,63 \\
\hline
\end{tabular}

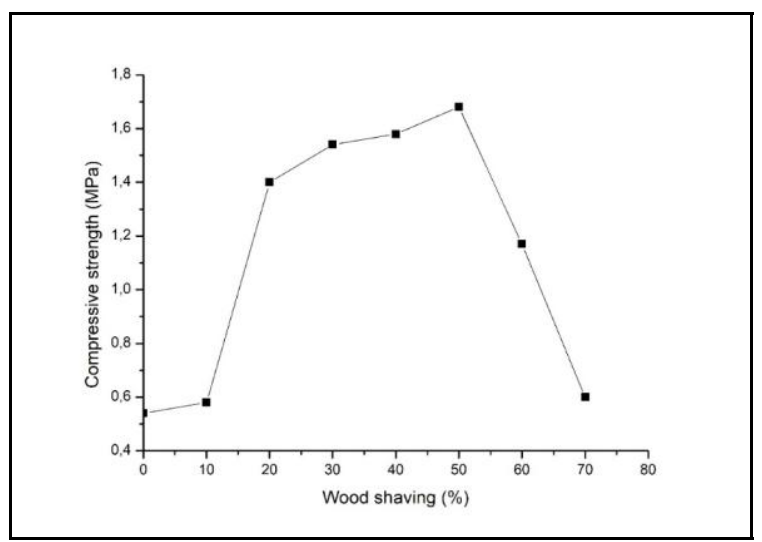

Fig.4 shows the compressive strength results of the adobe material containing wood shaving for all tested proportions $(10 \%, 20 \%, 30 \%, 40 \%, 50 \%, 60 \%$, and $70 \%$ ) by volume of wood shaving, the maximum strength is $1.68 \mathrm{MPa}$ which corresponds to the proportion $50 \%$. 


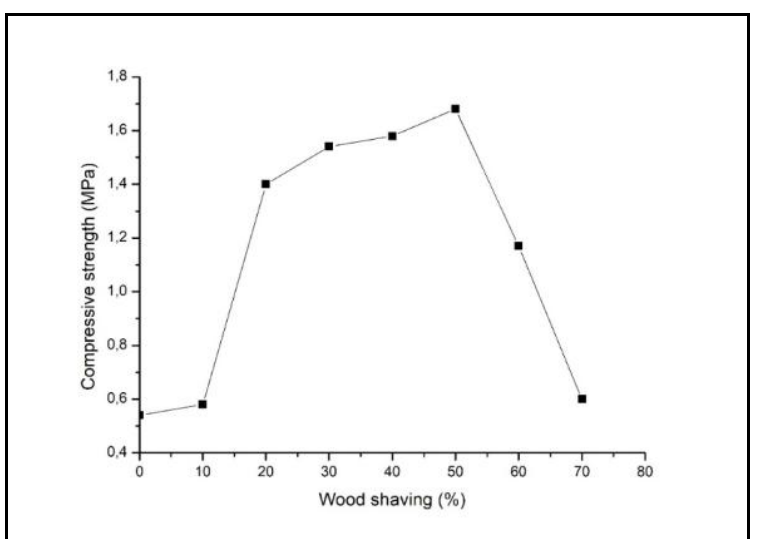

Fig.4. Compressive strengths of adobe material with different proportions of wood shaving

By comparing the results obtained during the first compression test on the adobe material Erreur ! Source du renvoi introuvable. with those obtained on the adobe with the wood shaving Erreur! Source du renvoi introuvable., it is quite clear that there is a significant improvement in the compressive strength.

\subsection{Tensile test}

As the bending tests are very much influenced by the experimental framework, a lot of research has been developed previously either on concrete or on earthen materials. The experimental program of this study was designed to evaluate the mechanical behaviour of the adobe and reinforced adobe specimens using the bending tensile test according to the standards EN 772-1[22], in order to evaluate the rigidity and load-bearing capacity of this material.

The mechanical tests were carried out at a constant deformation rate of $0.5 \mathrm{~mm} / \mathrm{min}$, each sample tested was of a prismatic rectangular shape with dimensions 40x40x160 mm Fig.1-b, six samples of the adobe material and seven samples of the adobe reinforced with different proportions of wood shaving $(10 \%, 20 \%, 30 \%$, $40 \%, 50 \%, 60 \%$, and $70 \%$ ), in total, thirteen samples were tested.

The average tensile strength found for the samples of the adobe material is about $0.22 \mathrm{MPa}$, and for the samples reinforced the maximum strength is $4.85 \mathrm{MPa}$ which corresponds to the proportion $50 \%$ by volume of wood shaving, and the average strength is $2.63 \mathrm{MPa}$ Erreur! Source du renvoi introuvable..

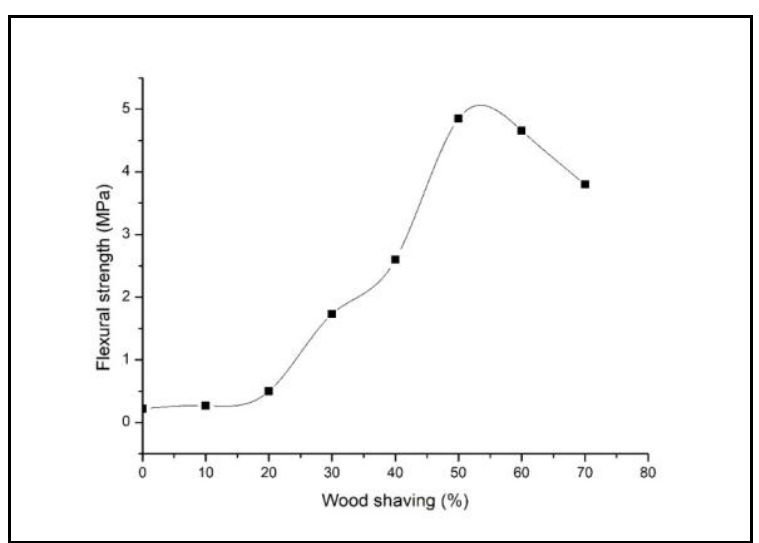

Fig.5. Flexural strength of adobe material with different proportions of wood shavingErreur ! Source du renvoi introuvable., has been obtained experimentally for samples of the adobe material (S1) it is around $73 \mathrm{MPa}$ and the reinforced one (S2-S3-S4-S5S6-S7-S8) is of an average value of $174.35 \mathrm{MPa}$. The mixture of adobe material and wood shaving has a higher modulus of elasticity than the modulus of the unreinforced material.

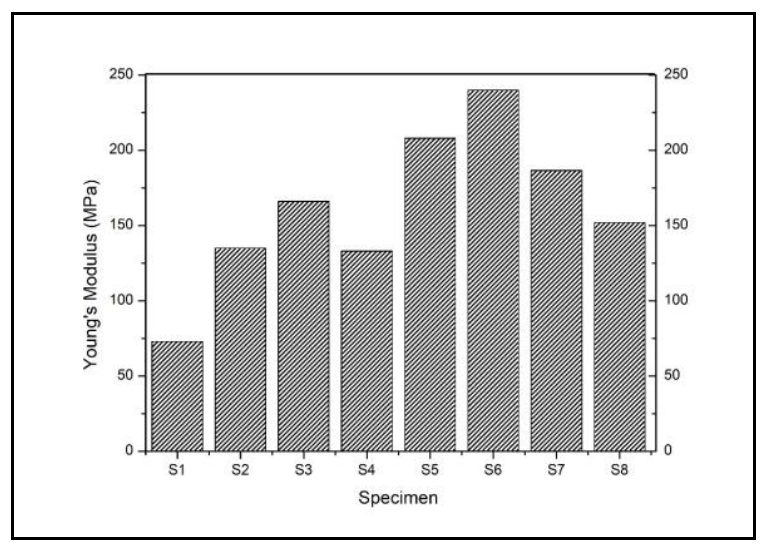

Fig.6. Young's Modulus of different specimens

By comparing the results obtained from the bending tensile tests Fig.5 with those obtained from the compression

tests

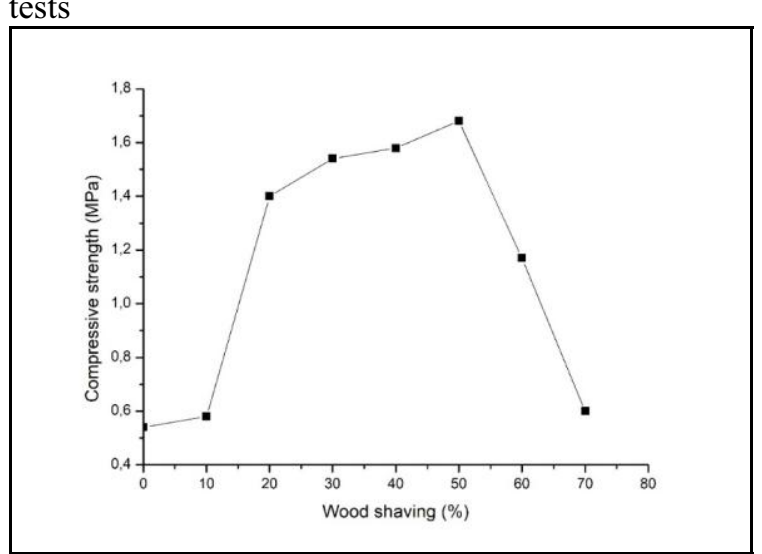


Fig.4, it is quite obvious that the compressive strength is more than the bending strength values for unreinforced adobe material, the ratio between bending and compressive strength for the same material is on average $40.7 \%$. On the other hand, we can see that the improvement in tensile strength for reinforced adobe is more significant than the compressive strength Fig.7.

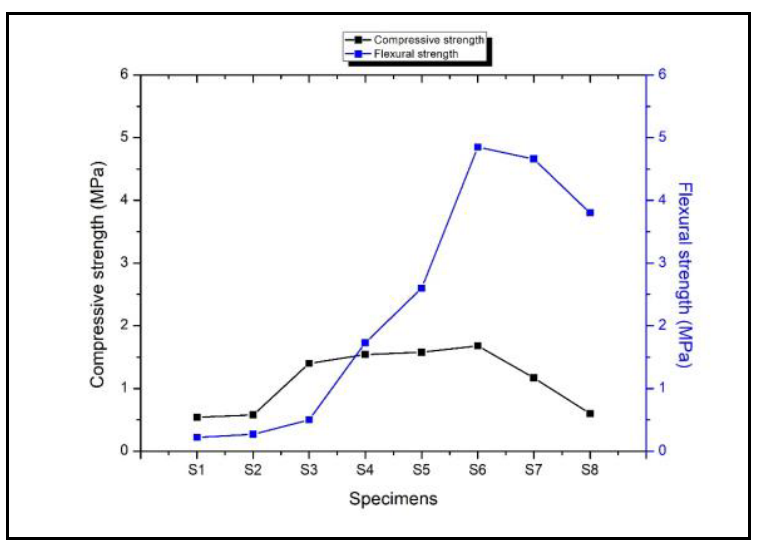

Fig.7. Comparison curve of compressive strengths and flexural strengths

\subsection{SEM test}

In order to explain the improvement of tensile strength in reinforced adobe, a complementary study was carried out on samples of the mixture of adobe material and wood shavings for the proportions $40 \%$ and $50 \%$ using the scanning electron microscope to characterize the morphology and observe the interfaces between wood shaving and the adobe material. The SEM makes it possible to quickly provide information on the morphology and elementary composition of a solid object. To avoid parasitic phenomena of charge accumulation, the sample must be absolutely clean, if possible flat and electrically conductive[8].

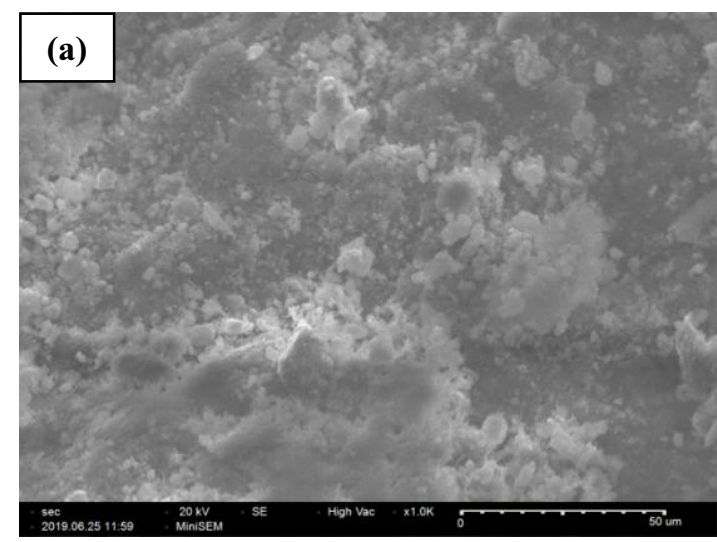

(b)
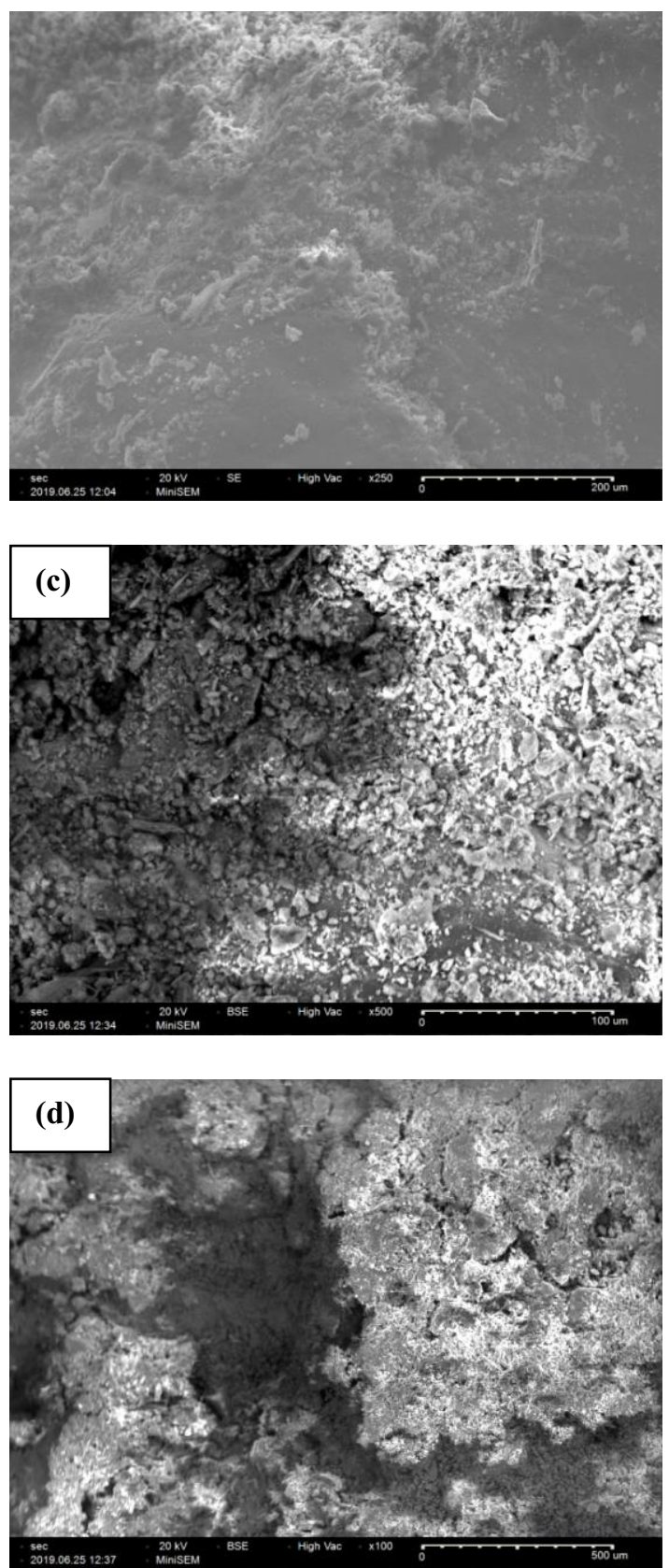

Fig.8. SEM image of fracture surface, (a) and (b): adobe microstructure, (c): adobe/wood shaving (50\% content), (d): adobe/wood shaving ( $40 \%$ content).

Scanning electronic microscopy (SEM) of the fractured surfaces of the adobe material without fibers is shown in

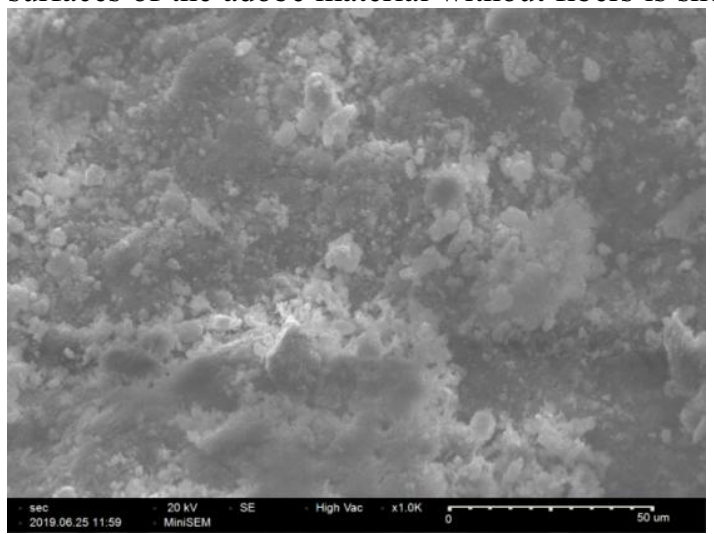



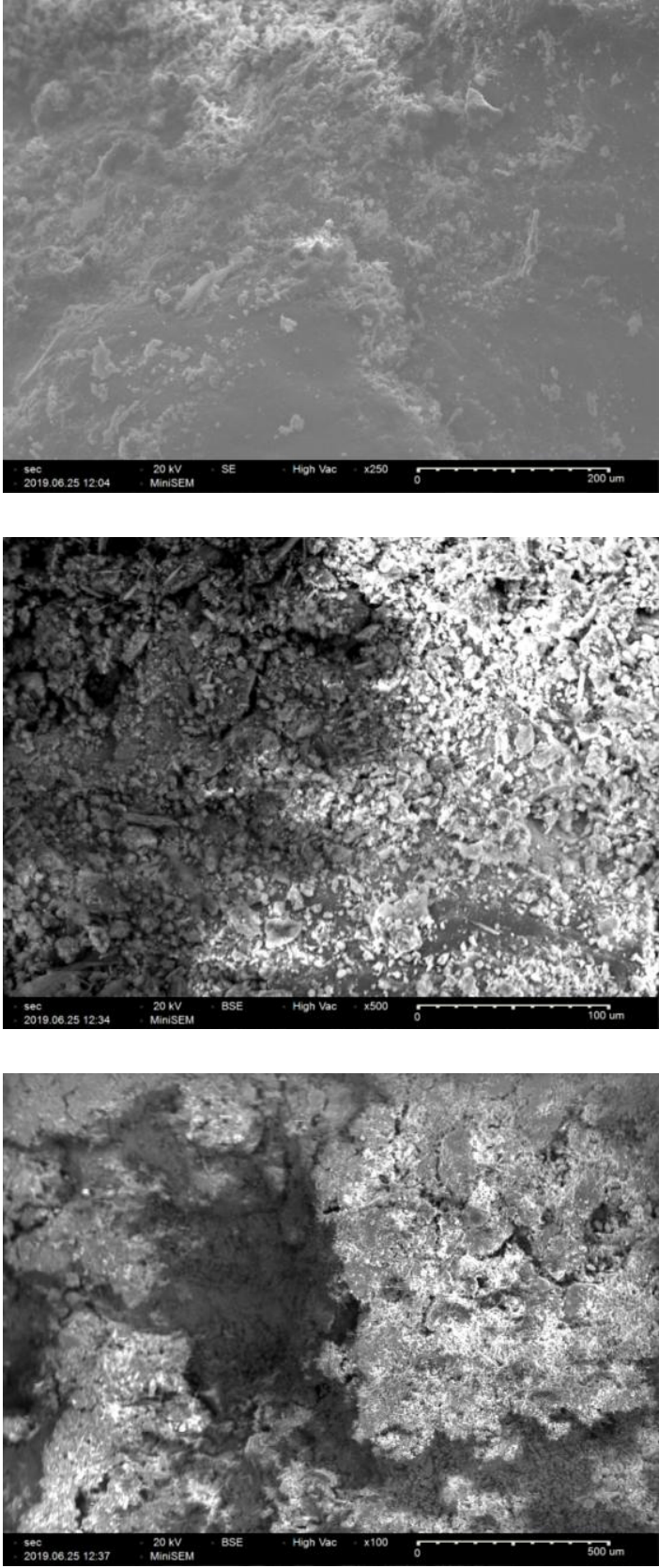

Fig.8-a-b, a heterogeneous microscopy with some cracks and large pores can be observed.
The micrograph of the adobe reinforced with $40 \%$ of
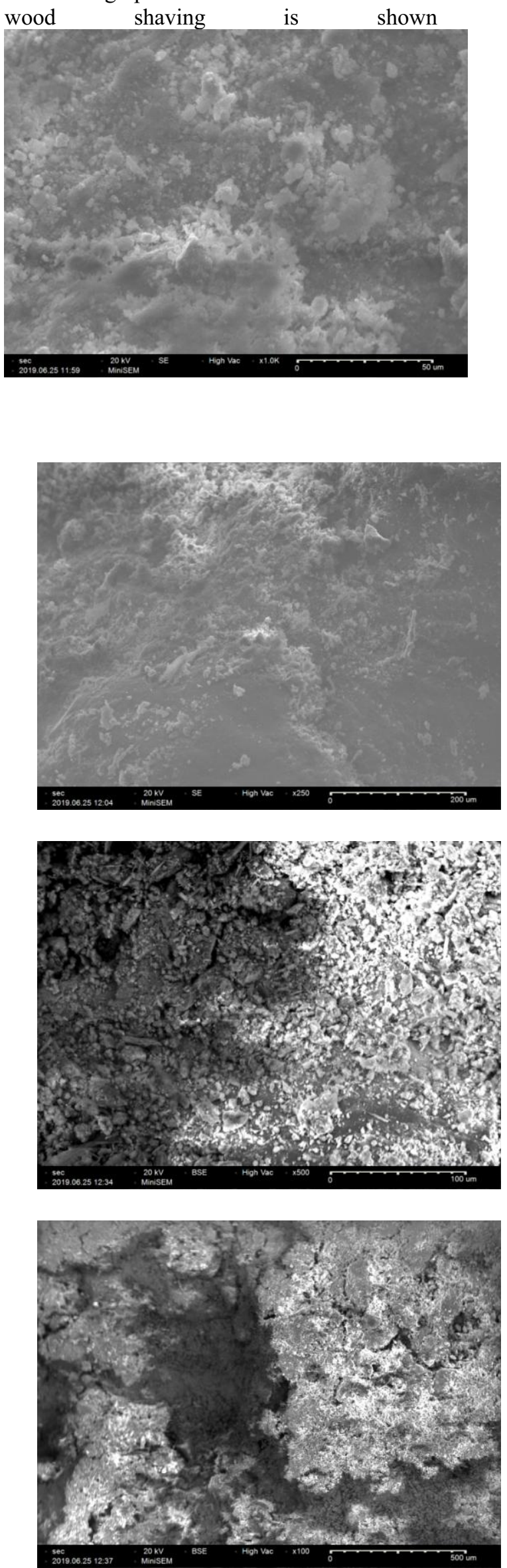
Fig.8-c, we observe that the rate of porosity is low, As It can be observed there is a strong adhesion between the matrix and the reinforcing material, and this can be explained by the nature of the two materials which results in a good interaction. In addition, the microstructure of the material seems very compact and without microcracks, which means that the wood fiber increased the toughness by protecting the composite of cracks propagation, and the absorption of fractures energy, which confirms the increase of the mechanical properties, and this can be attributed to the hydrophilicity of the wood fibers.

\section{By increasing the wood fibers content to reach $50 \%$,}
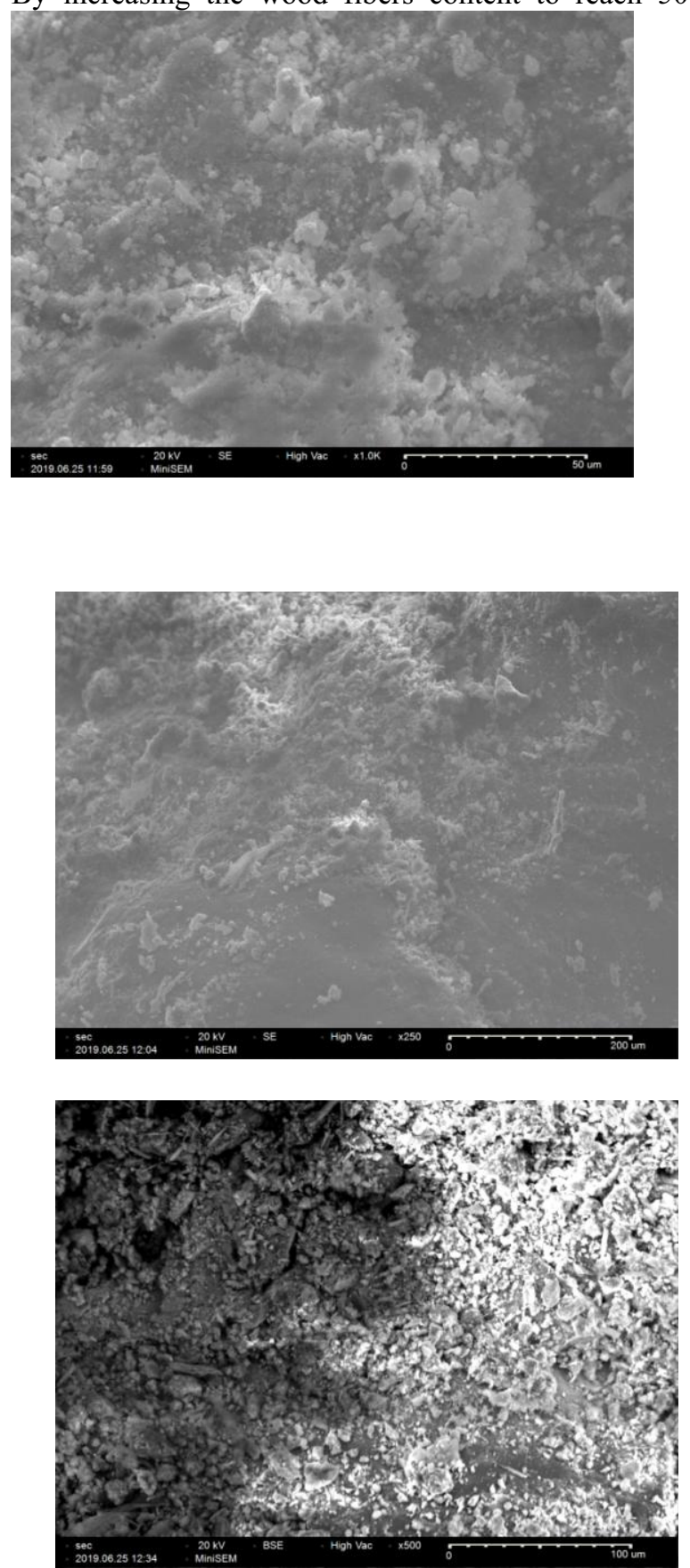

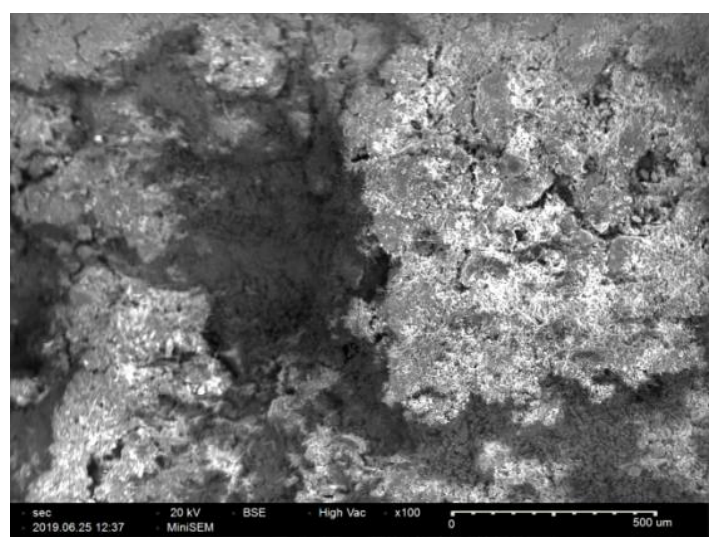

Fig.8-d, the composite material microscopy seems more homogeneous. The rough surface and the deformation of the wood fibers improved the link between the soil grains, which means a good cohesion.

Which remains that there is an important adhesion between the two components of the composite. The microstructural characterization confirmed that the use wood fibers to strengthen the adobe-based binder is a suitable alternative considering its important interaction with the matrix.

\section{Conclusion}

This research paper is in the interest of providing information on the mechanical and physical characterization and reinforcement techniques of the adobe material of the archaeological site Chellah (RabatMorocco). A mixture has been studied; the adobe material with wood shaving tested in different proportions, the experimental tests are carried out on different specimens, tested in compression and tensile bending, and afterwards the microscopic observation was performed using the scanning electronic microscopy.

Experimental tests show that mechanical properties such as tensile strength and modulus of elasticity can be identified by bending tensile tests, and that the adobe material resists both in compression and tensile stress, as well as the ratio between bending strength and compressive strength is $40 \%$. The addition of wood shaving has improved the performance of the mixture made by adobe and wood shaving in compression and tensile strength, and that the addition of wood fibers has a significant improvement in tensile strength as well as in compression.

The increase of the mechanical properties is related to the non-propagation of cracks due to the presence of wood fibers in the adobe matrix, which corresponds in our study to a wood shaving content of $50-40 \%$. 
The results obtained are required for the characterization of the adobe material used in the construction of the Chellah archaeological and historical site (RabatMorocco), and constitute important reference values to be taken into consideration in the restoration and rehabilitation of the site's buildings.

\section{References}

1. R. Daher, L'architecture en terre crue dans la vallée du Jourdain.pdf, UNIVERSITE PARISSACLAY, 2015

2. A. Salih and H. Amrani, (2011)

3. M. Terrisse, Les musées de sites archéologiques appréhendés en tant que vecteurs de développement local à travers trois études de cas préfigurant la mise en valeur opérationnelle du site de Chellah, thèse, Université de Maine, le Mans, 2011

4. CRATerre, Construire En Terre (France, 1979)

5. H. Varum, A. Costa, J. Fonseca, and A. Furtado, Procedia Engineering 114, 714 (2015)

6. H. Varum, A. Costa, H. Pereira, J. Almeida, and H. Rodrigues, 10 (2008)

7. V. Sharma, H. K. Vinayak, and B. M. Marwaha, Construction and Building Materials 93, 943 (2015)

8. R. Alavéz-Ramírez, P. Montes-García, J. Martínez-Reyes, D. C. Altamirano-Juárez, and Y. Gochi-Ponce, Construction and Building Materials 34, 296 (2012)

9. K. Ghavami, R. D. Toledo Filho, and N. P. Barbosa, Cement and Concrete Composites 21, 39 (1999)

10. B. Koohestani, A. Koubaa, T. Belem, B. Bussière, and $\mathrm{H}$. Bouzahzah, Construction and Building Materials 121, 222 (2016)

11. M. Li, M. Khelifa, and M. El Ganaoui, International Journal of Sustainable Built Environment 6, 587 (2017)

12. R. Sudin and N. Swamy, Journal of Materials Science 41, 6917 (2006)

13. S. Taj and M. A. Munawar, 17 (2007)

14. O. Onuaguluchi and N. Banthia, Cement and Concrete Composites 68, 96 (2016)

15. RPCT, (2013)

16. B. Quốc-Bảo, Stabilité des structures en pisé : Durabilité, caractéristiques mécaniques, thèse, L'INSTITUT NATIONAL DES SCIENCES APPLIQUEES DE LYON, 2008

17. V. Maniatidis and P. Walker, Journal of Materials in Civil Engineering 20, 230 (2008)

18. H. Van Damme and H. Houben, Cement and Concrete Research 114, 90 (2018)

19. G. Calatan, A. Hegyi, C. Dico, and C. Mircea, Procedia Technology 22, 259 (2016)

20. J. R. González-López, C. A. Juárez-Alvarado, B. Ayub-Francis, and J. M. Mendoza-Rangel, Construction and Building Materials 163, 179 (2018)
21. EN 196-1, Methods of Testing Cement - Part 1: Determination of Strength 2016

22. EN 772-1:2011, Methods of Test for Masonry Units - Part 1: Determination of Compressive Strength (2015) 